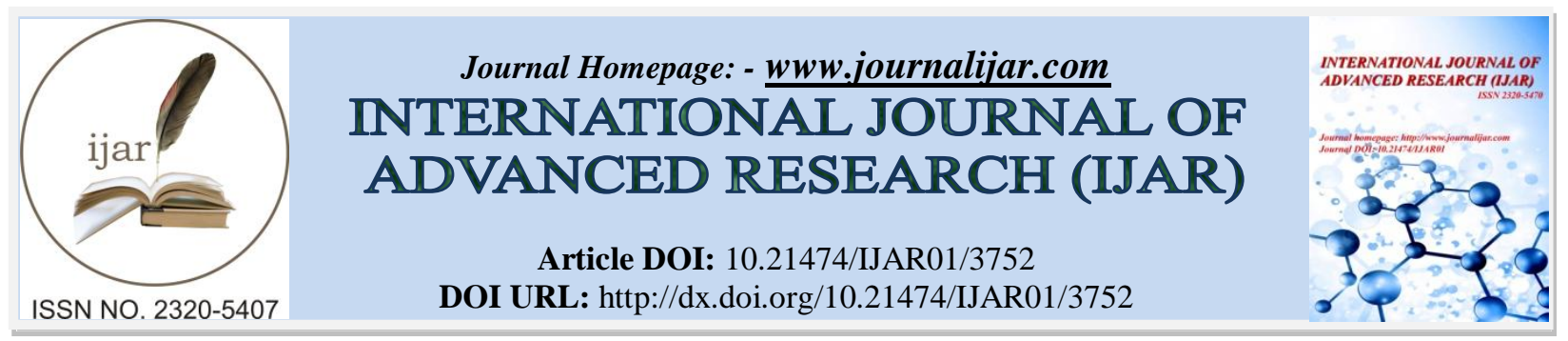

RESEARCH ARTICLE

\title{
TO EVALUATE THE ANTIMICROBIAL EFFICACY OF SIX MOUTHWASHES AGAINST STAPHYLOCOCCUS AUREUS AND STREPTOCOCCUS MUTANS - IN INVITRO STUDY
}

\section{Dr. A. Sudheer ${ }^{1}$, Dr. N. V. V. Satya Bhushan ${ }^{2}$, Dr. U. Siva Kalyan ${ }^{3}$, Dr. Kho Chai Chiang ${ }^{4}$ and Dr. S. Prameela ${ }^{1}$.}

1. Post Graduate student, Department of Oral and Maxillofacial Surgery, GITAM Dental College and Hospital, Visakhapatnam.

2. Professor and Head, Department of Oral and Maxillofacial Surgery, GITAM Dental College and Hospital, Visakha patnam.

3. Reader, Department of Oral and Maxillofacial Surgery, GITAM Dental College and Hospital, Visakhapatnam.

4. Senior Lecturer, Department of Oral and Maxillofacial Surgery, GITAM Dental College and Hospital, Visakhapatnam.

\section{Manuscript Info}

Manuscript History

Received: 16 January 2017

Final Accepted: 07 February 2017

Published: March 2017

Key words:-

Mouthwashes, Staphylococcus aureus,

Streptococcus mutans, Agar well

diffusion method.

\begin{abstract}
In-vitro comparative study to evaluate the efficacy of antimicrobial activity of Thymol(A), Chlorhexidine(B), Chlorhexidine plus triclosan (C), Cetylpyridinium chloride (D), Belleric myrobalan (E), Povidone iodine (F) mouthwashes against Staphylococcus aureus and Streptococcus mutans with distilled water as a control group was undertaken. The mouthwashes were tested at four different concentrations 1:4(25\%), 1:1(50\%), 3:4(75\%) and full strength (100\%). The antimicrobial activity was determined by using agar well diffusion method. The plates were allowed to incubated at $37^{\circ} \mathrm{c}$ for $24 \mathrm{hr}, 48 \mathrm{hr}$ and $72 \mathrm{hr}$. Chlorhexidine plus triclosan emerged as the most effective mouthwash against Staphylococcus aureus (30 $\mathrm{mm}$ to $35.33 \mathrm{~mm}$ ) and Streptococcus mutans $(19 \mathrm{~mm}$ to $27.5 \mathrm{~mm})]$ followed by Cetylpyridinium chloride, Chlorhexidine, Thymol, Belleric myrobalan. Povidone iodine and distilled water had no antimicrobial activity. It was concluded that the Chlorhexidine plus triclosan shows excellent antimicrobial activity but povidine iodine has no antimicrobial activity.
\end{abstract}

Copy Right, IJAR, 2017,. All rights reserved.

\section{Introduction:-}

Prevention of oral diseases is easier than cure ${ }^{1}$. Oral hygiene is an important aspect in our daily life for maintaining a healthy life style. The oral cavity contains more than 500 types of pathogenic and non-pathogenic bacteria, out of which 22 types are dominant. Improvement of oral health can influence the quality of life. Scientific research has shown that the use of mouthwashes (antimicrobial solutions) plays a vital role in the reduction of oral microbial load in the oral cavity.

Antimicrobial solutions are used for cleaning food remnants, decreasing oral malodour, prevention of plaque accumulation on tooth and gingival surfaces, used prior to and after oral surgical procedures in order to prevent oral pathogenic infections. Within the oral cavity, the most common microorganisms are staphylococcus aureus 
(formerly also called staphylococcus pyogenes) and Streptococcus mutans. Staphylococcus aureus is a gram positive, non motile, non spore forming, catalase positive cocci that occur in grape like clusters, it is a major human pathogen, responsible for a number of hospital-acquired infections, initially colonizes several locations in the human body, but the oral cavity and hands are the main reservoirs for propagation of this pathogen in the hospital environment ${ }^{1}$. Streptococcus mutans is a gram positive, non motile, non spore forming, catalase negative, facultative anaerobic cocci arranged in chains or pairs and commonly found in the oral cavity and has a major role in tooth decay formation and sore throat. S.mutans metabolise sucrose to lactic acid causes tooth decay.

There are 25 species of oral streptococci in human oral cavity ${ }^{2}$. Each of them develops specialised properties for colonisation in oral sites and constantly changes conditions to fight competing bacteria. Oral diseases can be initiated by imbalances in the microbial flora. In specific conditions, streptococci can change to opportunistic pathogen that can initiate the disease and damage the host. Oral streptococci is mentioned both as harmless and harmful bacteria.

To decrease infections in the Oral cavity different antimicrobial mouthwashes are used. So an in vitro study was under taken to known the antibacterial effectiveness of various mouthwashes such as A - Thymol, B Chlorhexidine, C - Chlorhexidine gluconate with triclosan, D - Cetylpyridinium chloride, E - Belleric myrobalan, F - Povidone iodine on Staphylococcus aureus and Streptococcus mutans.

\section{Aims and objectives of the study:-}

The aim of this invitro study is to evaluate efficiency of antimicrobial activity of different mouth washes such as Thymol, Chlorhexidine, Chlorhexidine plus triclosan, Cetylpyridinium chloride, Belleric myrobalan, Povidone iodine mouthwashes in different concentrations against staphylococcus aureus and Streptococcus mutans, by using culture media such as Nutrient agar and Blood agar respectively, compared with distilled water as a control group.

\section{Materials and Methods:-}

Six commonly used mouthwash products (Table 1) were evaluated for their antimicrobial activity compared with a control group (distilled water) in Department of Oral and Maxillofacial Surgery, GITAM Dental College and Hospital, Visakhapatnam, Andhra Pradesh.

\section{Microorganisms:-}

The test microorganisms Staphylococcus aureus, Streptococcus mutans were subcultured on specific media such as Nutrient Agar broth and Brain Heart Infusion Agar respectively incubated aerobically at $37^{\circ} \mathrm{C}$. The identification of all the microbes was confirmed by standard staining and biochemical methods.

\section{Identification of pathogen:-}

The oral specimens are plated on BHI agar, blood agar, and BHI broth for the isolation of the pathogenic strains in both aerobic and anaerobic conditions. The isolated strains were identified to the genus level by staining, microscopy, and biochemical tests. The agar slants of brain heart infusion agar are used for maintaining the identified culture. The culture slants were stored at $4^{\circ} \mathrm{C}$ in the refrigerator.

\section{Staining Characteristics:-}

The isolated colonies were stained by Grams staining procedure. The prepared smear was air-dried and heat fixed. Crystal violet was flooded over the smear for $1 \mathrm{~min}$ and drained. After washing, Gram's iodine was added and left for $1 \mathrm{~min}$. The smear was then washed in $95 \%(\mathrm{v} / \mathrm{v})$ ethanol for $30 \mathrm{sec}$. It was counterstained with Safranin for 2 min. After air drying, the smear was examined under oil immersion objective in a light microscope.

\section{Biochemical Characteristics:-}

The isolated strains were subcultured on BHI, blood agar and BHI broth. These Plates were incubated at $37^{\circ} \mathrm{C}$ overnight and cultural characteristics of the colonies were studied after incubation. Biochemical tests such as indole production test, methyl red test, citrate utilization test, catalase, indole, nitrate reduction, carbohydrate fermentation test, starch hydrolysis, urease test, hydrogen sulfide test, gelatin hydrolysis were performed. 


\section{Methods:-}

Antimicrobial effectiveness of various mouthwashes was assessed by using Agar well diffusion method:

\section{Agar well Diffusion Method:-}

The mouthwashes were tested at four different concentrations: 1:4(25\%), 1:1(50\%), 3:4(75\%) and full strength $(100 \%)$, taking sterile distilled water as the diluent, using agar well diffusion method or cup plate method. In this method, pure isolate of each microbe was subcultured on the recommended specific media for each microorganism at $37^{\circ} \mathrm{C}$ for $24 \mathrm{hrs}$. From each inoculated agar plate, a minimum of four colonies were touched with a sterile loop and transferred into a tube containing normal saline $(0.85 \%)$. A $100 \mu$ l volume of each mouthwash concentration (full strength, 3:4, 1:1, 1:4) and the control was propelled directly into the wells of the inoculated specific medias nutrient agar petri plates for Staphylococcus aureus and blood agar petri plates for Strptococcus mutans. The petri plates were allowed to stand for ten minutes for diffusion of the mouthwash to take place and incubated at $37^{\circ} \mathrm{c}$ for $24 \mathrm{hr}$, $48 \mathrm{hr}$ and $72 \mathrm{hr}$. The antimicrobial activity, indicated by an inhibition zone surrounding the well containing the mouthwash measures in $\mathrm{mm}$. The inhibition zone for different mouthwashes are measured and noted.

\section{Observations and Results:}

In the present study the antimicrobial activity of the six mouthwashes was evaluated against Staphylococcus aureus and Streptococcus mutans. It was determined by agar well diffusion method, was measuring growth of inhibition zone in millimeters $(\mathrm{mm})$ including the diameter of well $(6 \mathrm{~mm})$. The inhibition zone diameters were measured accordingly with dilutions of 1:4, 1:2, 3:4 and full strength, during the respective time intervals of 24hrs, 48hrs, $72 \mathrm{hrs}$

Based on the mean diameter of the zones of microbial inhibition produced by the six mouth washes in agar well diffusion method, against Staphylococcus aureus and Streptococcus mutans, the mouthwash ' $\mathrm{C}$ ' emerged as the most effective antimicrobial activity followed by mouthwash ' $\mathrm{D}$ ' that showed excellent level of antimicrobial activity. Following which mouthwash 'B' and 'A' showed good antimicrobial activity and finally, displaying very little antimicrobial activity was mouthwash 'E'. No antimicrobial activity against Staphylococcus aureus and Streptococcus mutans was elicited when tested with mouthwash F and distilled water.

Table 1:- Ingredients of six mouthwashes tested for antimicrobial potential.

\begin{tabular}{|c|l|l|}
\hline Mouthwash & \multicolumn{1}{|c|}{ Ingredients } & \multicolumn{1}{|c|}{ Active ingredients } \\
\hline A & $\begin{array}{l}\text { Purified water, sorbitol, alcohol, poloxamer 407, benzoic acid, } \\
\text { sodium saccharin, eucalyptol, flavour, methyl salicylate, } \\
\text { thymol, sodium benzoate, menthol }\end{array}$ & $\begin{array}{l}\text { Thymol } \\
\text { Eucalyptol } \\
\text { Methyl salicylate } \\
\text { Menthol }\end{array}$ \\
\hline B & $\begin{array}{l}\text { Chlorhexidine gluconate } 0.2 \% \text { w/v in a pleasantly flavoured } \\
\text { aqueous base. }\end{array}$ & Chlorhexidine gluconate \\
\hline C & $\begin{array}{l}\text { Chlorhexidine gluconate 0.2\% w/v, triclosan USP 0.05\% w/v, } \\
\text { sodium monoflourophosphate USP 0.07\% w/v in a pleasantly } \\
\text { flavoured aqueous base. }\end{array}$ & $\begin{array}{l}\text { Chlorhexidine gluconate } \\
\text { Triclosan }\end{array}$ \\
\hline D & $\begin{array}{l}\text { Water, glycerine, propylene glycol, sorbitol, poloxamer 407, } \\
\text { cetylpyridinium chloride, potassium sorbate, sodium fluoride, } \\
\text { sodium saccharin, menthal, citric acid }\end{array}$ & $\begin{array}{l}\text { Cetylpyridinium } \\
\text { chloride, }\end{array}$ \\
\hline E & $\begin{array}{l}\text { Belleric myrobalan } \text { (Bibhitaki) 10mg, Betel (Nagavalli) 10mg, } \\
\text { Pilu 5mg powders, Peppermint satva 0.4mg oils, Gandhayva } \\
\text { taila 1.2mg, Ela , other ingredients Sodium benzoate IP, } \\
\text { Bronopol IP, Potassium sorbate }\end{array}$ & $\begin{array}{l}\text { Belleric myrobalan } \\
\text { (Bibhitaki) }\end{array}$ \\
\hline F & $\begin{array}{l}\text { Povidone iodine IP 2\% w/v, absolute alcohol content 8.38\%v/v } \\
\text { in a mint flavour aqueous base. }\end{array}$ & Povidone iodine \\
\hline
\end{tabular}


Table 2:- Antimicrobial activity of mouthwashes against Staphylococcus aureus and Streptococcus mutans determined by agar well diffusion method by measuring diameter of growth of inhibition zones $(\mathrm{mm})$

\begin{tabular}{|c|c|c|c|c|c|c|c|c|}
\hline \multirow{2}{*}{$\begin{array}{l}\text { Dilutions } \\
\text { Mouthwash }\end{array}$} & \multicolumn{4}{|c|}{ Staphylococcus aureus } & \multicolumn{4}{|c|}{ Streptococcus mutans } \\
\hline & 24 hrs & $48 \mathrm{hrs}$ & $72 \mathrm{hrs}$ & Average & $24 \mathrm{hrs}$ & $48 \mathrm{hrs}$ & $72 \mathrm{hrs}$ & Average \\
\hline \multicolumn{9}{|l|}{$\mathrm{A}$} \\
\hline $1: 4(25 \%)$ & 16 & 16 & 16 & 16 & 16.5 & 16.5 & 16.5 & 16.5 \\
\hline $1: 2(50 \%)$ & 17 & 17.5 & 17.5 & 17.33 & 17 & 17 & 17 & 17 \\
\hline $3: 4(75 \%)$ & 19 & 20 & 20 & 19.66 & 18.5 & 18.5 & 18.5 & 18.5 \\
\hline$(100 \%)$ & 21 & 21.5 & 21.5 & 21.33 & 18.5 & 19 & 19 & 18.83 \\
\hline \multicolumn{9}{|l|}{$\mathrm{B}$} \\
\hline $1: 4(25 \%)$ & 18 & 18.5 & 18.5 & 18.33 & 19 & 19.5 & 19.5 & 19.33 \\
\hline $1: 2(50 \%)$ & 19 & 19.5 & 19.5 & 19.33 & 21 & 21.5 & 21.5 & 21.33 \\
\hline $3: 4(75 \%)$ & 21 & 21.5 & 21.5 & 21.33 & 22 & 22.5 & 22.5 & 22.33 \\
\hline$(100 \%)$ & 24 & 25 & 25 & 24.66 & 23.5 & 25 & 25 & 24.5 \\
\hline \multicolumn{9}{|l|}{$\mathrm{C}$} \\
\hline $1: 4(25 \%)$ & 30 & 30.5 & 30.5 & 30.33 & 23 & 23.5 & 23.5 & 23.33 \\
\hline $1: 2(50 \%)$ & 31 & 31.5 & 31.5 & 31.33 & 25 & 25 & 25 & 25 \\
\hline $3: 4(75 \%)$ & 33 & 33.5 & 33.5 & 33.33 & 26 & 27 & 27.5 & 26.83 \\
\hline$(100 \%)$ & 35 & 35.5 & 35.5 & 35.33 & 28 & 29 & 29.5 & 28.33 \\
\hline \multicolumn{9}{|l|}{$\mathrm{D}$} \\
\hline $1: 4(25 \%)$ & 22 & 22.5 & 22.5 & 22.33 & 20 & 21 & 21 & 20.66 \\
\hline $1: 2(50 \%)$ & 24 & 24.5 & 24.5 & 24.33 & 23 & 23.5 & 23.5 & 23.33 \\
\hline $3: 4(75 \%)$ & 27 & 27.5 & 28 & 27.50 & 25 & 25.5 & 26 & 25.5 \\
\hline$(100 \%)$ & 29 & 29.5 & 29.5 & 29.33 & 26 & 26.5 & 27 & 26.5 \\
\hline \multicolumn{9}{|l|}{$\mathrm{E}$} \\
\hline $1: 4(25 \%)$ & 0 & 0 & 0 & 0 & 0 & 0 & 0 & 0 \\
\hline $1: 2(50 \%)$ & 0 & 0 & 0 & 0 & 0 & 0 & 0 & 0 \\
\hline $3: 4(75 \%)$ & 16 & 16 & 16 & 16 & 14 & 14 & 14 & 14 \\
\hline$(100 \%)$ & 18 & 18.5 & 18.5 & 18.33 & 16 & 16 & 16.5 & 16.17 \\
\hline \multicolumn{9}{|l|}{$\mathrm{F}$} \\
\hline $1: 4(25 \%)$ & 0 & 0 & 0 & 0 & 0 & 0 & 0 & 0 \\
\hline $1: 2(50 \%)$ & 0 & 0 & 0 & 0 & 0 & 0 & 0 & 0 \\
\hline $3: 4(75 \%)$ & 0 & 0 & 0 & 0 & 0 & 0 & 0 & 0 \\
\hline$(100 \%)$ & 0 & 0 & 0 & 0 & 0 & 0 & 0 & 0 \\
\hline Distilled water & 0 & 0 & 0 & 0 & 0 & 0 & 0 & 0 \\
\hline
\end{tabular}

\section{Discussion:-}

P.K. Sreenivasan .et.al ${ }^{3}$ (2013) stated that the human oral cavity and its various ecological niches (i.e. dorsal tongue, buccal mucosa, subgingival spaces, etc.) harbour substantial numbers of Gram-positive and Gram-negative bacteria. Dental plaque is one of the most thoroughly investigated types of microbial biofilms with clinical studies clearly. The oral cavity is a major gateway to the human body. The microorganisms colonizing one area of the oral cavity have a significant probability of spreading on contiguous epithelial surfaces to neighbouring sites. Microorganisms from the oral cavity have been shown to cause a number of oral infectious diseases, including caries (tooth decay), periodontitis (gum disease), endodontic (root canal) infections, alveolar osteitis (dry socket), and tonsillitis. Evidence is accumulating which links oral bacteria to a number of systemic diseases, including cardiovascular disease, stroke, and pneumonia.

In the present study determination of the antimicrobial activity of six mouthwashes, and its effectiveness of active ingredients was done. The antimicrobial activity of the mouthwashes were assessed where statistical ranking procedures were used to place the six different mouthwashes following the order of antimicrobial effectiveness. The results revealed variations in their effectiveness against the two tested microorganisms. Based on the mean diameter of the zones of microbial inhibition produced by the mouthwashes in agar well diffusion method, tested against staphylococcus aureus and streptococcus mutans, chlorhexidine gluconate with triclosan showed best results where as Cetylpyridinium chloride also emerged as a mouthwash with the excellent antimicrobial activity. Chlorhexidine 
gluconate and Thymol (essential oils) showed good antimicrobial activity and finally, displaying very little antimicrobial activity was Belleric myrobalan while povidone iodine had no antimicrobial activity.

The mouthwash ' $A$ ' contains active ingredients such as four phenol-related essential oils (thymol, eucalyptol,menthol and methyl salicylate) which claim to penetrate the plaque biofilm and thus kill micro-organisms that causes gingivitis. Furgang D .et.al ${ }^{4}$ (2005) stated that the mouthwashes display broad spectrum antimicrobial activity, prevent bacterial aggregation, slow bacterial multiplication, retard plaque maturation and decrease plaque mass and pathogenicity.

The mouthwashes ' $\mathrm{B}$ ' and ' $\mathrm{C}$ ' contains active ingredients. They are Chlorhexidine gluconate is a cationic biguanide with broad spectrum antimicrobial activity. It is most effective mouthwash for reducing plaque and gingivitis. Arweiler NB .et.al ${ }^{5}$ (2001) stated that the Chlorhexidine has an important feature of substantivity,that helps in prolonged adherence of the antiseptic to the oral surfaces (mucosa \& teeth) \&its slow release at effective doses that guarantees the persistence of its microbial activity. Kamal Raj Current recommendations are for twice-daily i.e. chlorhexidine to be used only as a short-term adjunct, or as an aid in disinfection of surgical sites, to improve wound healing, or as a short-term treatment of halitosis. It is not recommended for long-term use due to its numerous adverse effects. These include tooth and restoration staining, soft tissue staining, increased calculus deposition, unpleasant taste, taste alteration, burning sensation, desquamation and mucosal irritation. Chlorhexidine may also potentiate oral discomfort in patients with chemotherapy-induced mucositis, xerostomia or ulcerative oral mucosal conditions.

The mouthwash ' $\mathrm{C}$ ' contains active ingredients, Chlorhexidine gluconate and Triclosan. Triclosan is synthetic nonionic chlorinated phenolic agent with antiseptic qualities. Witt J.et.al ${ }^{6,7}(2005)$ ststed that broad-spectrum efficacy on Gram-positive and most Gram-negative bacteria. It is also effective against mycobacterium, anaerobic bacteria, the spores and fungi of the Candida species. The mechanism of its antiseptic action is by acting on the microbial cytoplasmic membrane, inducing leakage of cellular constituents and thereby causing lysis of the micro-organisms.

The mouthwash ' $\mathrm{D}$ ' contains active ingredients, they are Cetylpyridinium chloride is a quaternary ammonium compound with antiseptic and antimicrobial properties. Narinder Pahwa .et.al ${ }^{8}$ (2011) stated that the cationic and binds to bacterial surfaces causing disruption of the cell membrane, leakage of intracellular components and disruption of metabolism. Mouthwashes containing cetylpyridinium chloride inhibit and reduce plaque build-up. Hadi Darvishikhezri et $\mathrm{al}^{3}$ (2013), investigated that the mouthwashes containing cetylpyridinium chloride with alcohol and cetylpyridinium chloride without alcohol were most effective antimicrobial activity against supragingival plaque microorganism.

The mouthwash 'E' contains active ingredients such as Belleric myrobalan. Rupali Mahajan .et.al ${ }^{9}$ (2016) stated that the antimicrobial properties, analgesic and antioxidant properties.

The mouthwash ' $F$ ' contains active ingredients such as Povidone iodine, an iodophore in which iodine is linked to povidone that displays an affinity for the cell membrane there by delivering free iodine directly to the bacterial cell surface. AdamietzIA.et.al ${ }^{10}(1998)$ stated that the broad spectrum of activity against bacteria, fungi, protozoa and viruses. The mouthwash has been shown to be effective in reducing plaque and gingivitis and may be a useful adjunct to routine oral hygiene. It also reduces the incidence, severity and duration of radiation mucositis. Absorption of excess iodine has been postulated to result in metabolic complications, however this is not of concern in patients without pre-existing thyroid disease and if the patient spits out the solution.

Chlorhexidine gluconate with triclosan has shown most effective antimicrobial activity at full strength concentration against Staphylococcus aureus and Streptococcus mutans, which causes dental caries and oral infections respectively in comparison with the other five mouthwashes (i.e Thymol, Chlorhexidine, Cetylpyridinium chloride, Belleric myrobalan and Povidone iodine).

\section{Conclusion:-}

According to this study, Chlorhexidine gluconate with triclosan has shown most effective antimicrobial activity at full strength concentration against Staphylococcus aureus and Streptococcus mutans which causes dental caries and oral infections respectively in comparison with the other five mouthwashes (i.e Thymol, Chlorhexidine, Cetylpyridinium chloride, Belleric myrobalan and Povidone iodine). 


\section{References:-}

1. Kamal Raj Aneja, Radhika Joshi, Chetan Sharma. The antimicrobial potential of ten often used mouthwashes against four dental caries pathogens. Jundishapur J Microbiol, 2010; 3: 15-27.

2. Janan Ghapanchi, Afagh moattari, Fateneh Lavaee, Mahmood Shakib. The antibacterial effect of four mouthwashes against streptococcus mutans and escherichia coli. J Pak Med Assoc 2015; 65(4).

3. P.K. Sreenivasan,V.I. Haraszthy, J.J. Zambon. Antimicrobial efficacy of $0.05 \%$ cetylpyridinium chloride mouthrinses. Lett Appl Microbiol 2013; 56(1): 14-20

4. Furgang D, Fine DH, Sinatra K, Charles C, McGuire A, Kumar LD; In vivo antimicrobial effectiveness of an essential oil-containing mouthrinse $12 \mathrm{~h}$ after a single use and 14 days' use. J Clin Periodontol 2005; 32: 33540.

5. Arweiler NB, Netuschil L, Reich E. Alcohol-free mouthrinse solutions to reduce supragingival plaque regrowth and vitality. A controlled clinical study. J Clin Periodontol 2001;28:168-74.

6. Witt J, Ramji N, Gibb R, Dunavent J, Flood J, Barnes J. Antibacterial and antiplaque effects of a novel, alcoholfree oral rinse with cetylpyridinium chloride. J Contemp Dent Pract 2005;6:1-9.

7. Panagakos FS, Volpe AR, Petrone ME, DeVizio W, Davies RM, Proskin HM. Advanced oral antibacterial/antiinflammatory technology: A comprehensive review of the clinical benefits of a triclosan/copolymer/fluoride dentifrice. J Clin Dent 2005;16:1-19.

8. Narinder Pahwa, Atul Kumar, Siddharth Gupta. Short term clinical effectiveness of a $0.07 \%$ cetylpyridinium chloride mouth rinse in patients undergoing fixed orthodontic appliance treatment. Saudi Dent J 2011; 23(3): $135-141$.

9. Rupali Mahajan, Paramjit Kaur Khinda, Amarjit Singh Gill, Jyotinder Kaur,S. P. Saravanan, Akhilesh Shewale, Meenu Taneja and Vaibhav Joshi. Comparison of Efficacy of $0.2 \%$ ChlorhexidineGluconate and Herbal Mouthrinses on DentalPlaque: An in vitro Comparative Study. European Journal of Medicinal Plants 2016; 13(2): $1-11$.

10. Adamietz IA, Rahn R, Böttcher HD, Schafer V, Reimer K, Fleischer W; Prophylaxis with povidone-iodine against induction of oral mucositis by radiochemotherapy. Support Care Cancer 1998;6: 373-377.

11. Arul selvan K, Rajendra singh.C, Prabhu T. Antibacterial activity of bee propolis against clinical strains of streptococcus mutans and synergism with chlorhexidine. International Journal of Pharmaceutical Studies and Research 2015; 2 (1):85-90.

12. Lidia Ruiz, Cesar Escribano, Patricia Veiga-Crespo, Tomas G.Villa and Teresa Vinuesa. In vitro" comparative experimental study of antimicrobial action of mouth washing products. Bull Group Int Rech Sci Stomatol Odontol 2007; 48: 32-38.

13. Amal Sabry Othman. In vitro evaluation of six different mouthwashes against six oral pathogens. International Journal of Drug Delivery 2015; 7: 44-51.

14. Hadi Darvishi khezri, Mohammad Ali Haidari Gorji, Ali Morad and Heidari Gorji. Comparison of the antibacterial effects of matrica \& Persica ${ }^{\mathrm{TM}}$ and chlorhexidine gluconate mouthwashes in mechanically ventilated ICU patients: a double blind randomized clinical trial. Rev Chilena Infectol 2013; 30 (4): 368-373.

15. Mai M.Helmy and Riham O.Bakr. In vitro Comparison of the Antimicrobial Activity of Five Herbal Extracts, and Selected Mouthwashes Marketed in Egypt against Cariogenic Streptococcus Mutans. Egypt J Med Microbiol 2014; 23 (1).

16. Naiana B. Da Silva, Adilis K.F.Alexandria, aline L.Delima, Ligia V.Claudino, Thiago F.De Oliveira Carneiro, Adalberto C.Da Costa, Ana M.G.Valenca, Alessandro L. Cavalcanti. In vitro antimicrobial activityof mouth washes and herbal products against dental biofilm-forming bacteria. Contemporary clinical dentistry 2012; 3 (3). 